\title{
Effects of Canopy and Multi-Epoch Observations on Single-Point Positioning Errors of a GNSS in Coniferous and Broadleaved Forests
}

\author{
Tong Feng ${ }^{1,+}$, Shilin Chen ${ }^{1,2,+} \mathbb{D}^{\mathbb{D}}$, Zhongke Feng ${ }^{1, *}$, Chaoyong Shen ${ }^{1,3}$ and Yi Tian ${ }^{1,4}$ \\ 1 Precision Forestry Key Laboratory of Beijing, Beijing Forestry University, Beijing 100083, China; \\ fengtong@bjfu.edu.cn (T.F.); chenshilin@piesat.cn (S.C.); shency@gzchsy.cn (C.S.); tianyi01@tyut.edu.cn (Y.T.) \\ 2 Piesat Information Technology Co., Ltd., Beijing 100195, China \\ 3 The third Institute of Surveying and Mapping of Guizhou Province, Guiyang 550004, China \\ 4 Polytechnic Institute, Taiyuan University of Technology, Taiyuan 030027, China \\ * Correspondence: zhongkefeng@bjfu.edu.cn \\ + Tong Feng and Shilin Chen contributed equally to this work.
}

Citation: Feng, T.; Chen, S.; Feng, Z.; Shen, C.; Tian, Y. Effects of Canopy and Multi-Epoch Observations on Single-Point Positioning Errors of a GNSS in Coniferous and Broadleaved Forests. Remote Sens. 2021, 13, 2325. https://doi.org/10.3390/rs13122325

Academic Editor:

Nereida Rodriguez-Alvarez

Received: 28 April 2021

Accepted: 10 June 2021

Published: 13 June 2021

Publisher's Note: MDPI stays neutral with regard to jurisdictional claims in published maps and institutional affiliations.

Copyright: (c) 2021 by the authors. Licensee MDPI, Basel, Switzerland. This article is an open access article distributed under the terms and conditions of the Creative Commons Attribution (CC BY) license (https:/ / creativecommons.org/licenses/by/ $4.0 /)$.

\begin{abstract}
Global navigation satellite systems (GNSS) can quickly, efficiently, and accurately provide precise coordinates of points, lines, and surface elements, plus complete surveys and determine various boundary lines in forest investigations and management. The system has become a powerful tool for dynamic forest resource investigations and monitoring. GNSS technology plays a unique and important role in estimating timber volume, calculating timber cutting area, and determining the location of virgin forest roads and individual trees in forests. In this study, we quantitatively analyzed the influence of crown size and observation time on the single-point positioning accuracy of GNSS receivers for different forest types. The GNSS located single points for different forest types and crown sizes, enabling the collection of data. The locating time for each tree was more than $10 \mathrm{~min}$. Statistical methods were used to analyze the positioning accuracy of multi-epoch data, and a model was developed to estimate the maximum positioning errors under different forest conditions in a certain positioning time. The results showed that for a continuous positioning time of approximately $10 \mathrm{~min}$, the maximum positioning accuracies in coniferous and broadleaf forests were obtained, which were 12.13 and $15.11 \mathrm{~m}$, respectively. The size of a single canopy had no obvious influence on the single-point positioning error of the GNSS, and canopy density was proven to be closely related to the positioning accuracy of a GNSS. The determination coefficients $\left(R^{2}\right)$ in the regression analysis of the general model, coniferous forest model, and broadleaved forest model that were developed in this study were $0.579,0.701$, and 0.544 , respectively. These results indicated that the model could effectively predict the maximum positioning error in a certain period of time under different forest types and crown conditions at middle altitudes, which has important guiding significance for forest resource inventories and precise forest management.
\end{abstract}

Keywords: tree canopy; multi-epoch data; GNSS system; single-point positioning; positioning error model

\section{Introduction}

Many forest resource surveys require highly accurate field measurements of the spatial locations of trees. According to the different requirements of practical applications, the accuracy of locating a single tree or sample site varies from several centimeters to several meters [1]. With increasing attention focused on the spatial locations of trees and sample plots in forestry surveys, exploring which factors are the dominant factors affecting spatial positioning and determining how to quantitatively express the impact of those factors on positioning accuracy are becoming necessary $[2,3]$.

The development of satellite positioning is rapidly providing new options for forest resource managers to obtain timely and highly accurate location data [4]. Global navigation 
satellite systems (GNSSs) mainly include GPS in the United States, Russia's GLONASS global satellite navigation system, the European Union's Galileo system, and China's Beidou satellite navigation system, BDS. Among the four navigation and positioning systems, GPS and GLONASS are available globally, and the other two systems remain under construction. At the end of June 2020, China successfully launched the 55th navigation satellite of the Beidou system and the last global networking satellite of Beidou-3. So far, the constellation deployment of the Beidou global navigation satellite system has been completed. Recently, airborne laser scanning to create forest resource inventories has become a practical method for mapping large areas of forest resources in detail $[5,6]$. The practical application of airborne laser scanning relies on the widespread use of millimeter-scale receivers and the differential positioning of field sample maps. The acquisition cost of these receivers is high, and managing differential positioning data is time-consuming in forest resource inventories, especially in remote areas of reference stations that require time to collect the data and are located away from the forest [7]. In many countries, continuously operating reference stations are used for differential positioning. However, in remote areas, the distance from a reference station reduces the accuracy of this positioning. If a precise position can be obtained by a technique that does not rely on differential correction, the data processing of the receiver can be simplified, and the cost can be reduced. GNSSs have increasingly been playing roles in positioning forest fires [8], mapping forest resources [9], inventorying forest resources [10], positioning fixed sample sites [11], mapping roads [12], and measuring other natural resources [13].

Positioning with a GNSS in a forest can be blocked by trunks and branches, or the satellite signal can be reflected to produce a multipath effect; therefore, the receiver cannot be located in the forest, or the positioning accuracy is low [14,15]. The canopy is an important variable affecting the statistical characteristics of GNSSs, such as path loss, attenuation, and polarization [16]. The canopy density is a key factor affecting GNSS positioning accuracy, and many studies have been conducted on the influence of density indexes on positioning accuracy [11,17-19]. In general, the smaller the canopy density, the wider the sky, the higher the positioning accuracy and vice versa. The forest type is also an important factor affecting the positioning of GNSSs. Although many previous experimental studies were conducted, these studies were not able to effectively quantify the extent to which forest types affect the positioning of GNSSs [20]. The positioning time of GNSSs under the tree crowns is also an important factor affecting the positioning accuracy of GNSSs. Reasonable positioning time and appropriate positioning accuracy are important considerations for forest resource inventories and work efficiency [21]. The season is another important factor. It is generally thought that the presence of foliage has a strong impact on GNSS signals, reducing the accuracy of positioning, whereas positioning accuracy is higher during seasons without leaves [22-24].

To explore the quantitative effects of these factors on the positioning errors of GNSSs, a GNSS equipment system was used to conduct experiments in different forest types and to quantitatively analyze and express the results. The main objectives of this study were: (1) to explore the impact of coniferous and broadleaved tree species on GNSS positioning errors; (2) to quantitatively analyze the potential relationship between positioning time and positioning accuracy, and to determine the optimal positioning time for forest inventories; (3) to determine the influence of crown size on GNSS positioning errors in different forest types; and (4) to develop the maximum error model of single-point static positioning in GNSSs for a certain positioning time. The main directions in this research are positioning under canopies and positioning under complex conditions $[25,26]$.

\section{Materials and Methods}

\subsection{Study Area}

For the study area, we chose the Changpoling National Forest Park in Baiyun District, Guiyang city, Guizhou province, China. The selected study area is a typical artificial forest in the southwestern mountainous area of China, with a total area of 1075 hectares; this area 
is an important part of the green belt around the city of Guiyang (Figure 1). The altitude of the area ranges from 2000 to $2500 \mathrm{~m}$; the long-term annual minimum temperature and maximum daily air temperature averages are 12 and $19{ }^{\circ} \mathrm{C}$, respectively; and the forest coverage rate is as high as $82.96 \%$. The forest types include coniferous forest, broadleaved forest, and mixed coniferous and broadleaved forest. The main species are Populus L., Pinus, Pinus armandii Franch, Pinus massoniana Lamb, Ginkgo biloba L., Liriodendron chinensis, and Eucommia ulmoides. Additional shrubs and herbs are found in the forest. In this study, because the selected sampling data area was small, the topographical terrain, slope direction, elevation, latitude, and longitude did not vary considerably. Therefore, the impact of these factors on the single-point positioning accuracy of the Galaxy 6 GNSS among different trees was not considered in this study. However, due to the relatively large forest density, the multipath effect will have a certain impact on the positioning accuracy. In order to reduce the influence of the multipath effect on the positioning accuracy, we extended the observation time appropriately.

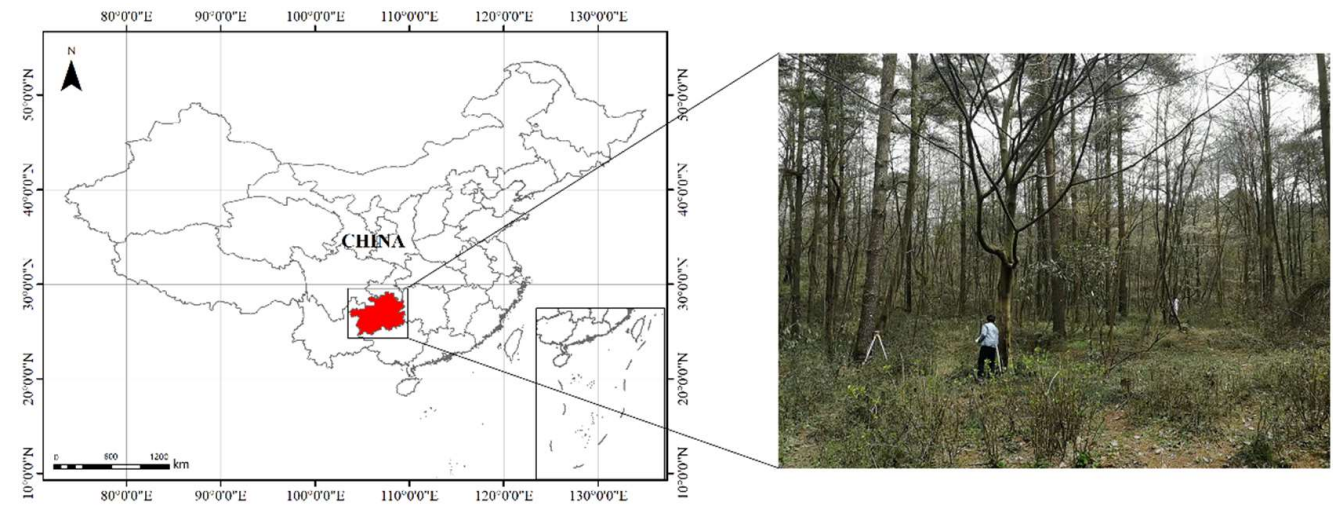

Figure 1. Overview of the forest distribution in the study area.

\subsection{Data Acquisition}

We used a Galaxy 6 RTK (Figure 2a) (South Surveying \& Mapping Technology Co., Ltd.; http:/ / www.southinstrument.com/ (15 March 2021), Guangzhou city, China) to acquire the location data of the coniferous and broadleaf forests in the field. The positioning output frequency of the Galaxy 6 RTK GNSS is 1-50 Hz, and the initial reliability is greater than $99.99 \%$, which greatly improves the accuracy of carrier positioning by relying on highly reliable carrier tracking technology. The lithium battery capacity of the device is $6800 \mathrm{mAh}$, and the continuous working time is greater than $30 \mathrm{~h}$ in the static standard mode. The static measuring accuracy of this device is theoretically $2.5 \mathrm{~mm}$. With every $1 \mathrm{~km}$ increase in measuring distance between two points, the positioning accuracy decreases by $1 \mathrm{~mm}$. The horizontal positioning accuracy of the single-point code differential GNSS is $0.25 \mathrm{~m}+1 \mathrm{ppm}$ RMS, which can provide relatively more stable data by relying on mature CORS technology. The technical specifications of Galaxy 6 RTK instrument are shown in Table 1. In this experiment, we set the output frequency of the Galaxy 6 RTK GNSS to $1 \mathrm{~Hz}$; that is, the sampling interval was $1 \mathrm{~s}$. We conducted static single-point positioning for each tree in the experiment for at least $10 \mathrm{~min}$ to obtain tree location information. 


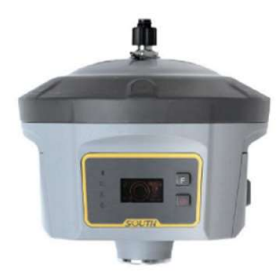

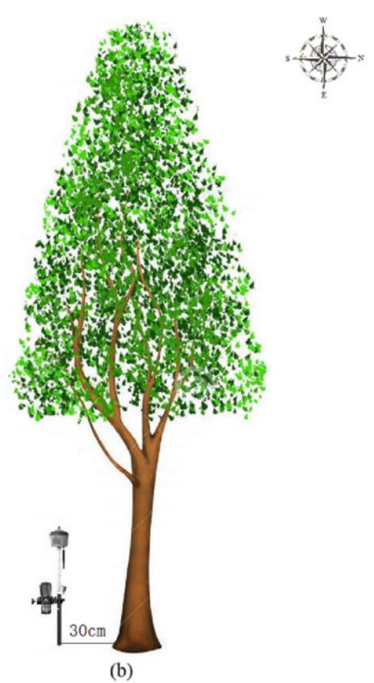

(b)

Figure 2. (a) The Galaxy 6 RTK GNSS and (b) the acquisition of tree location information in the field. (The measured and reference values of the tree location information were obtained $30 \mathrm{~cm}$ south of the tree).

Table 1. Technical specifications of the Galaxy 6 RTK instrument.

\section{SPECIFICATIONS}

\begin{tabular}{|c|c|c|}
\hline \multicolumn{3}{|c|}{ SPECIFICATIONS } \\
\hline Surveying performance & $\begin{array}{l}\text { Signal Tracking } \\
\text { GNSS Feature }\end{array}$ & $\begin{array}{c}\text { BDS B1, B2, } \\
\text { GPS L1C/A, L1C, L2C, L2E, L5 } \\
\text { GLONASS L1C/A, L1P, L2C/A, L2P, L3 } \\
\text { Galileo GIOVE-A, GIOVE-B, E1, E5A, E5B } \\
\text { QZSS, WAAS, MSAS, EGNOS, GAGAN, SBAS } \\
\text { Positioning output rate: } 1 \text { HZ-50 HZ } \\
\text { Initialization reliability: }>99.99 \%\end{array}$ \\
\hline Positioning precision & $\begin{array}{c}\text { Code Differential GNSS Positioning } \\
\text { Static GNSS Surveying } \\
\text { Real-Time Kinematic Surveying (Baseline }<30 \mathrm{~km} \text { ) } \\
\text { Network RTK }\end{array}$ & $\begin{array}{c}\text { Horizontal: } 0.25 \mathrm{~m}+1 \text { ppm RMS } \\
\text { Vertical: } 0.50 \mathrm{~m}+1 \text { ppm RMS } \\
\text { SBAS positioning accuracy: typically }<5 \mathrm{~m} \text { 3DRMS } \\
\text { Horizontal: } 2.5 \mathrm{~mm}+0.5 \text { ppm RMS } \\
\text { Vertical: } 5 \mathrm{~mm}+0.5 \text { ppm RMS } \\
\text { Horizontal: } 8 \mathrm{~mm}+1 \text { ppm RMS } \\
\text { Vertical: } 15 \mathrm{~mm}+1 \text { ppm RMS } \\
\text { Vertical: } 15 \mathrm{~mm}+0.5 \text { ppm RMS }\end{array}$ \\
\hline Hardware performance & $\begin{array}{c}\text { Dimension } \\
\text { Weight } \\
\text { Battery life } \\
\text { Wireless Modem }\end{array}$ & $\begin{array}{c}155 \mathrm{~mm}(\text { diameter })^{*} 137 \mathrm{~mm} \text { (height) } \\
1.44 \mathrm{~kg} \text { (including battery) } \\
\text { More than } 30 \mathrm{~h} \text { (static mode), more than } 15 \mathrm{~h} \text { (RTK } \\
\text { mode), (providing the } 7^{*} 24 \mathrm{~h} \text { battery solution) } \\
\text { External radio transmitter } 5 \mathrm{~W} / 25 \mathrm{~W} \\
\text { Working frequency } 410-470 \mathrm{MHz}\end{array}$ \\
\hline Data transmission/format & $\begin{array}{c}\text { Data Transmission } \\
\text { Data Format }\end{array}$ & $\begin{array}{l}\text { USB data transmission, FTP download, HTTP download } \\
\text { Static data format: STH Rinex2.x and Rinex3.x etc. } \\
\text { Differential data format: CMR+, CMR } \times \text {, RTCM 2.1, } \\
\text { RTCM 2.3, RTCM 3.0, RTCM3.1, RTCM3.2 } \\
\text { GPS output data format: NMEA0183, PJK plane } \\
\text { coordinates, binary code, Trimble GSOF }\end{array}$ \\
\hline
\end{tabular}

Using the Galaxy 6 RTK + CORS base station to perform single-point static positioning in open areas, the Gauss Kruger coordinates of $A\left(x_{A}, y_{A}, h_{A}\right)$ and $B\left(x_{B}, y_{B}, h_{B}\right)$ in the WGS-84 coordinate system were determined. The horizontal distance between the two points was $30 \mathrm{~m}$. Twenty independent single-point positioning observations were captured of the two points, $\mathrm{A}$ and $\mathrm{B}$, and the mean values were taken as the real coordinate values of the points. Then, the total station was used to observe the positions of 29 trees according to the two known coordinate values, and the coordinate value of each tree was obtained with the polar coordinate method as the reference value. We used the total station to measure the coordinate value of the position of each tree $30 \mathrm{~cm}$ to the south (RTK position 
in Figure 2b) because we could not directly locate a tree's core coordinates when locating a tree's position in practice; therefore, the coordinate values were measured a certain distance from the tree's center ( $30 \mathrm{~cm}$ to the south). In addition, we used the total station to measure the coordinates of five open area points (no trees or other obstacles nearby) based on the coordinates of the known points, $A$ and $B$, and labeled them $C\left(x_{C}, y_{C}, h_{C}\right), D\left(x_{D}, y_{D}, h_{D}\right)$, $\mathrm{E}\left(\mathrm{x}_{\mathrm{E}}, \mathrm{y}_{\mathrm{E}}, \mathrm{h}_{\mathrm{E}}\right), \mathrm{F}\left(\mathrm{x}_{\mathrm{F}}, \mathrm{y}_{\mathrm{F}}, \mathrm{h}_{\mathrm{F}}\right)$, and $\mathrm{G}\left(\mathrm{x}_{\mathrm{G}}, \mathrm{y}_{\mathrm{G}}, \mathrm{h}_{\mathrm{G}}\right)$.

The five points without shelter (C, D, E, F, and G) were positioned using Galaxy 6 RTK GNSS equipment to obtain the GNSS single point positioning error, $\sigma_{0}$, without a canopy or other shelter. The formulas are defined as follows:

$$
\begin{gathered}
x_{0}=\frac{\sum_{i=1}^{k} \Delta x_{i}^{2}}{k} ; y_{0}=\frac{\sum_{i=1}^{k} \Delta y_{i}^{2}}{k} ; \\
\sigma_{0}=\sqrt{\left(x_{0}^{2}+y_{0}^{2}\right)}
\end{gathered}
$$

where $\Delta x_{i}$ and $\Delta y_{i}$ are the differences between the measured values obtained by the Galaxy 6 RTK GNSS in the $x$ and $y$ directions and the reference values obtained by the total station, respectively; $x_{0}$ and $y_{0}$ are the positioning system errors of the Galaxy 6 RTK system in the $x$ and $y$ directions, respectively, and $k$ is the number of the 5 points in the open area.

The coordinate measurements of 29 coniferous and broadleaved trees in the plot were obtained using the Galaxy 6 RTK system $30 \mathrm{~cm}$ in the southward direction of each tree (Figure 2b). To obtain accurate tree position coordinate information and account for the influence of positioning time on work efficiency, the single-point positioning time of each tree position was at least $10 \mathrm{~min}$ or longer to ensure that sufficient epoch data were obtained.

Field data were collected in April 2019 (Figure 3). The tree structure parameters obtained in the field included diameter at breast height (DBH), tree height (h), canopy (D), and tree species (coniferous or broadleaved). The DBH of each tree was measured using a measuring tape with millimeter accuracy. The heights of the trees were measured using a mobile RGBD-SLAM tree measurement system developed by the Beijing Key Laboratory of Precision Forestry [6]; the tree height accuracy measured by this system was between 10 and $50 \mathrm{~cm}$ and was obtained using two optical cameras and a field camera with infrared depth. A tape measure was used to measure the size of the canopy, and the species were identified by a forestry professional. The structural characteristics of coniferous and broadleaved forests based on field forest inventory data are shown in Table 2.

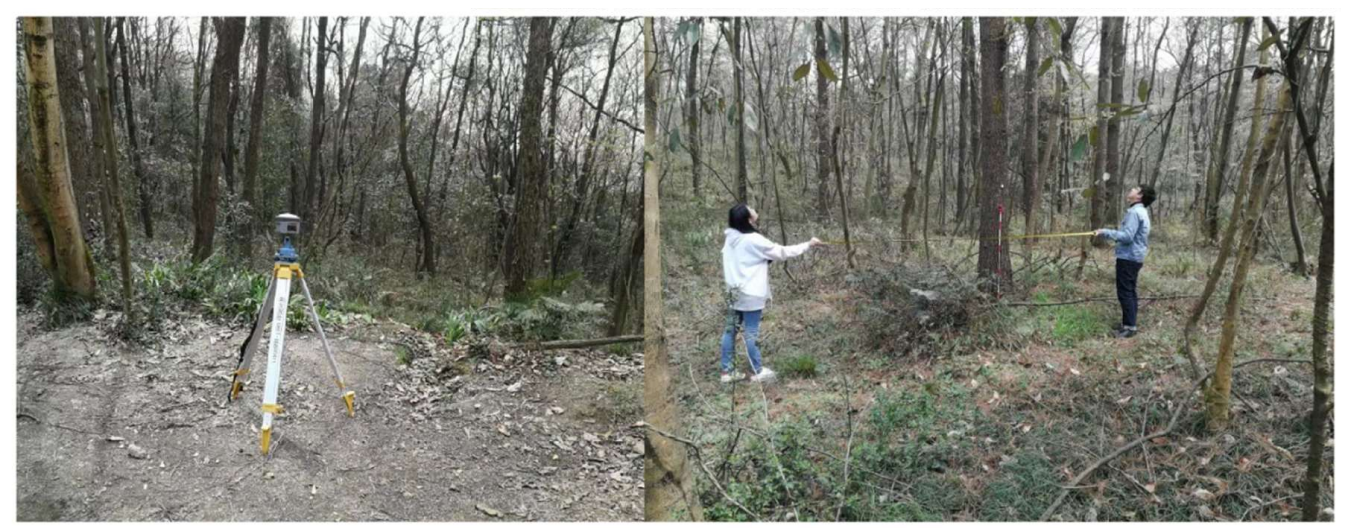

Figure 3. Data acquisition of tree structure parameters in the field experiments. 
Table 2. Structural characteristics of coniferous and broadleaved forest based on field forest inventory data.

\begin{tabular}{|c|c|c|c|c|c|c|c|c|c|c|}
\hline \multirow{2}{*}{ Forest Type } & \multirow{2}{*}{ Number } & \multicolumn{3}{|c|}{ Tree Crown (m) } & \multicolumn{3}{|c|}{$\mathrm{DBH}(\mathrm{cm})$} & \multicolumn{3}{|c|}{ Tree Height (m) } \\
\hline & & Mean & Min & Max & Mean & Min & $\operatorname{Max}$ & Mean & Min & $\operatorname{Max}$ \\
\hline Coniferous forest & 12 & 4.9 & 3.0 & 8.0 & 32.2 & 21.0 & 43.6 & 23.8 & 13.0 & 34.0 \\
\hline Broadleaved forest & 17 & 6.4 & 3.0 & 10.0 & 23.7 & 12.4 & 38.2 & 18.9 & 10.0 & 34.0 \\
\hline
\end{tabular}

\subsection{Data Processing}

In this study, we only considered the positioning accuracy of the RTK GNSS plane coordinates and did not analyze the elevation positioning accuracy. The data obtained by the Galaxy 6 RTK GNSS for single-point positioning were in .sth format. Information regarding each epoch in RTKGNSS positioning cannot be calculated in this format. Therefore, we first converted the data in .sth format into the general Rinex 4.0 format using Gnssadj software (South Surveying \& Mapping Technology Co., Ltd., version 4.06, http: / /www. southinstrument.com/ (15 March 2021). Then, RTKLIB software (an open-source program package for GNSS positioning, version 2.4.2, http:/ / www.rtklib.com/ (15 March 2021) was used to solve the epoch data in the positioning data. This software, which has relatively high accuracy, is the most commonly used tool for calculating epoch data. Therefore, we input the converted data into the RTKPOST application program, which is a part of RTKLIB. Because the Galaxy 6 RTK GNSS only receives carrier information from the GPS and GLONASS satellite systems when acquiring single-point positions, the singlepoint positioning information of trees in the sample plot only included positioning data from the GPS and GLONASS satellite systems. By analyzing the configuration file of the remote sensing satellite data set, the spatial continuity test parameters of the corresponding remote sensing satellite data set were obtained; Based on the remote sensing satellite data set and the spatial continuity test parameters, we observed that the remote sensing satellite data set did not have serious missing data, which indicated that the satellite signal had good continuity [27]. The coordinates of the epoch data calculated from singlepoint positioning data are the geodesic latitude and longitude coordinates in the WGS-84 coordinate system, i.e., two sets of data with completely different coordinate systems, the WGS-84 and CGCS2000 coordinate systems, which were obtained by the total station. COORD (an open-source program package for transforming coordinates, version 4.2) is a commonly used coordinate conversion software program that converts coordinate information among the Beijing-54 coordinate system, the Xi'an-80 coordinate system, the WGS-84 coordinate system, and the WGS-72 coordinate system using seven or four parameters. We used this software to convert the geodetic coordinates and plane coordinate points in the WGS- 84 coordinate system. Before the coordinate transformation, we first determined the central meridian of the study area. A 3-degree zoning projection ensured the necessary accuracy for a large-scale topographic map. The central meridian of the area was determined with a 3-degree banding tape number and the longitude information of the study area.

Although the basic definition of the WGS-84 coordinate system is consistent with that of the CGCS2000 coordinate system, their reference ellipsoids are similar, and only the oblateness of the ellipsoid constant is slightly different. However, to ensure strict consistency with the coordinates measured by the total station, the plane coordinates of WGS-84 were converted to the plane coordinates of CGCS2000. The calculated data of each epoch were compared with the corresponding data measured by the total station. The positioning error between the measured data and the reference value is defined as follows:

$$
\Delta p_{i}=\sqrt{\Delta x_{i}^{2}+\Delta y_{i}^{2}}
$$

where $\Delta x_{i}$ and $\Delta y_{i}$ are the differences between the measured values obtained by the Galaxy 6 RTK GNSS in the $x$ and $y$ directions and the reference values obtained by the total station, respectively. 
The epoch data of the single-point positioning of each tree were sorted according to the positioning error, $\Delta p_{i}$, from large to small. Then, in accordance with $1,2,5,10 \ldots 400$, 500 , and all epochs, the epoch data were grouped to obtain the average positioning error and the positioning errors in the $x$ and $y$ directions were analyzed separately. By analyzing and comparing the mean values of different multi-epoch data, the quantity of multi-epoch data with minimum positioning error was determined.

\subsection{Statistical Analysis}

To determine the maximum positioning error of different amounts of multi-epoch data at a single positioning time point under the tree canopy using the Galaxy 6 RTK GNSS system, we calculated bias and determined the root mean square error (RMSE) of the coordinates to compare the positioning accuracy of the RTK GNSS system with the reference values measured by the total station. BIAS and RMSE are defined as follows:

$$
\begin{gathered}
B I A S_{x}=\frac{\sum_{i=1}^{m}\left(\Delta x_{i}\right)}{m} ; B I A S_{y}=\frac{\sum_{i=1}^{m}\left(\Delta y_{i}\right)}{m} \\
R M S E_{x}=\sqrt{\frac{\sum_{i=1}^{m} \Delta x_{i}^{2}}{m}} ; R M S E_{y}=\sqrt{\frac{\sum_{i=1}^{m} \Delta y_{i}^{2}}{m}}
\end{gathered}
$$

where $\Delta x_{i}$ and $\Delta y_{i}$ are the differences between the measured values obtained by the Galaxy 6 RTK GNSS in the $x$ and $y$ directions and the reference values obtained by the total station, respectively; and $m$ is the total number of trees measured.

Root mean square coordinate error $\left(R M S E_{x y}\right)$ is one of the most commonly used indicators for evaluating measurement accuracy in geodetic surveying, and this measurement is also a characteristic of point set accuracy [24]. $R M S E_{x y}$ is calculated as follows:

$$
R M S E_{x y}=\sqrt{0.5\left(R M S E_{x}^{2}+R M S E_{y}^{2}\right)}
$$

\subsection{Construction of the Positioning Error Model}

To further explore the relationships between the RTK GNSS positioning accuracy and tree crown size, tree species, and multi-epoch observation data, we built a general model of the RTK GNSS positioning error under different tree crowns:

$$
\sigma_{i}^{2}=\sigma_{0}^{2}+\frac{a^{2}}{n}+b_{1}^{2} * D_{1 i}^{2}+b_{2}^{2} * D_{2 i}^{2}
$$

where $\sigma_{i}$ is the error of the ith tree positioning, $n$ is the number of epochs, $i$ indicates the ith tree, $a^{2}$ is a coefficient related to the number of epochs, $b_{1}$ and $b_{2}$ are coefficients associated with the crown diameters of coniferous and broadleaved forests, respectively; and $D_{1 i}$ and $D_{2 i}$ are the crown diameter values of coniferous and broadleaved forest species, respectively.

In our constructed positioning error model, when the ith tree was a coniferous tree, the coefficient $b_{2}$ of $D_{2 i}$ was 0 , and then the form of the error model was as follows: $\sigma_{i}=\sqrt{\sigma_{0}^{2}+\frac{a^{2}}{n}+b_{1}^{2} * D_{1 i}^{2}}$. Similarly, when the ith tree was a broadleaved tree, the form of the error model was as follows: $\sigma_{i}=\sqrt{\sigma_{0}^{2}+\frac{a^{2}}{n}+b_{2}^{2} * D_{2 i}^{2}}$. We analyzed the correlations between independent variables $\mathrm{n}$ and $\mathrm{D}$ and the dependent variable $\sigma$ using IBM SPSS Statistics 23 software (International Business Machines Corporation, https://www.ibm. com/cn-zh, 12 June 2021), which offers advanced statistical analysis, a vast library of machine-learning algorithms, text analysis, open-source extensibility, integration with big data, and seamless deployment in applications. We also used the software to conduct linear regression analysis on our established general model to verify the reliability and accuracy of the model. In addition, coniferous and broadleaved forest species were modeled 
and analyzed separately to determine the impact of different forest types on positioning accuracy.

\section{Results}

For a single navigation and positioning system, a GNSS needs to track at least four satellites for three-dimensional positioning; for a dual system, the system needs to track at least five satellites. Therefore, there is a case when positioning epoch data are missing in actual GNSS positioning data processing due to satellite signal loss. The satellite distribution at a certain moment during the acquisition of single-point positioning data in the field is shown in Figure 4. We found that of 29 trees, only 1 had fewer than 500 epoch data points (489) when calculating the multi-epoch data, which did not affect our calculation and analysis of the epoch data.

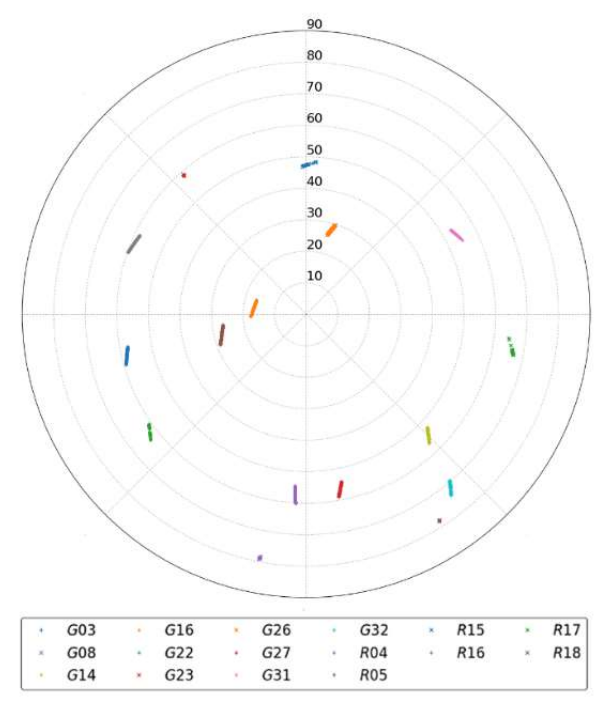

Figure 4. Satellite distribution in the sky at a certain time when single-point positioning trees in the field using the Galaxy 6 GNSS.

\subsection{Positioning Accuracy of Different Multi-Epoch Data}

The epoch data of the single-point positioning of 29 trees in the sample were grouped by different quantities, and the mean positioning error of each group of epoch data was calculated. The positioning error results of different groups of multi-epoch data are shown in Table 3. From the table, with increases in the amount of multi-epoch data, the positioning errors of bias and RMSE on the $x$ and $y$ axes generally showed a decreasing trend, and the total positioning error RMSE $_{x y}$ also decreased gradually. The GNSS single-point positioning error was greatly reduced from the 1 epoch group to the 90 epoch groups. BIAS $_{x}$ and BIAS decreased from -11.80 and 19.75 to -7.76 and $14.74 \mathrm{~m}$, respectively;

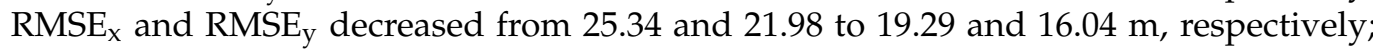
and the overall positioning RMSE of a single point also decreased from 23.72 to $17.74 \mathrm{~m}$, significantly improving the positioning accuracy. With the increase in the amount of multiepoch data, the accuracy of single-point positioning improved, but the rate of improvement was lower than that of the previous multi-epoch data group. The positioning time was approximately $10 \mathrm{~min}$; the longer the time allowed for determining a single-point location, the more accurate the location of the tree. 
Table 3. Single-point positioning accuracy error analysis of multi-epoch data.

\begin{tabular}{cccccc}
\hline Number of Epochs & BIAS $_{\mathbf{x}}(\mathbf{m})$ & BIAS $_{\mathbf{y}}(\mathbf{m})$ & RMSE $_{\mathbf{x}}(\mathbf{m})$ & RMSE $_{\mathbf{y}}(\mathbf{m})$ & $\boldsymbol{R M S E}_{\mathbf{x y}}(\mathbf{m})$ \\
\hline 1 & -11.80 & 19.75 & 25.34 & 21.98 & 23.72 \\
2 & -12.80 & 19.48 & 26.28 & 21.72 & 24.11 \\
5 & -9.25 & 19.88 & 23.91 & 22.42 & 23.18 \\
10 & -9.60 & 17.80 & 21.44 & 19.11 & 20.31 \\
30 & -8.52 & 17.12 & 20.37 & 18.87 & 19.63 \\
60 & -8.03 & 15.31 & 19.69 & 16.63 & 18.22 \\
90 & -7.76 & 14.74 & 19.29 & 16.04 & 17.74 \\
120 & -7.61 & 14.33 & 19.01 & 15.64 & 17.41 \\
240 & -7.24 & 13.34 & 18.27 & 14.68 & 16.57 \\
300 & -7.11 & 13.00 & 17.99 & 14.35 & 16.27 \\
400 & -6.93 & 12.49 & 17.58 & 13.88 & 15.84 \\
500 & -6.72 & 12.01 & 17.13 & 13.43 & 15.39 \\
total & -7.65 & 11.61 & 17.01 & 13.13 & 15.19 \\
\hline
\end{tabular}

All trees in the sample plot were also precisely located using the CSRS-PPP service provided by the Canadian Geodetic Survey of Natural Resources Canada, which has high computational accuracy. The error plane results of the precise single-point calculation of positioning data in the RTK GNSS are shown in Figure 5. As shown in the figure, the positions of all trees in the $y$-axis direction (i.e., longitude direction) were overestimated, and the positions in the $x$-axis direction (i.e., latitude direction) were both overestimated and underestimated, which were evenly distributed on both sides of the $x=0$ line.

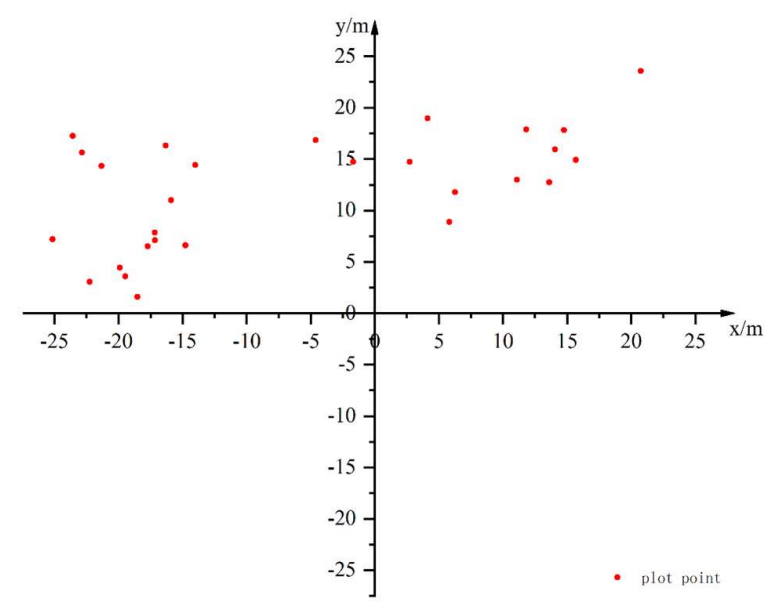

Figure 5. The error plane distribution of the precise solution results from the single-point positioning of trees.

The differences between the static single-point precise solution results and the actual reference coordinate values of all trees' locations in the sample plot are listed in Table 4. The maximum bias was $31.41 \mathrm{~m}$, the minimum bias was $10.61 \mathrm{~m}$, and the median of the positioning error was $19.81 \mathrm{~m}$. Positioning errors less than $15 \mathrm{~m}$ in the $x$-axis direction and $y$-axis direction accounted for $44.83 \%$ and $68.97 \%$ of the total, respectively. From the data in Table 4, with increasing tree crown cover, the error of single-point positioning did not increase or decrease significantly for either the broadleaved or coniferous forest species. 
Table 4. Galaxy 6 RTK GNSS single-point positioning precision solution positioning error.

\begin{tabular}{|c|c|c|c|c|c|}
\hline Tree ID & Tree Species & Tree Crown/m & $\Delta \mathrm{x}(\mathrm{m})$ & $\Delta y(m)$ & $\Delta p(\mathrm{~m})$ \\
\hline 1 & Broadleaved forest & 6 & 5.81 & 8.88 & 10.61 \\
\hline 2 & Broadleaved forest & 10 & 6.28 & 11.79 & 13.35 \\
\hline 3 & Coniferous forest & 7 & 11.10 & 13.00 & 17.09 \\
\hline 4 & Coniferous forest & 4 & 15.69 & 14.91 & 21.64 \\
\hline 5 & Broadleaved forest & 8 & 14.07 & 15.94 & 21.26 \\
\hline 6 & Broadleaved forest & 4 & 13.61 & 12.75 & 18.65 \\
\hline 7 & Coniferous forest & 5 & 11.81 & 17.88 & 21.43 \\
\hline 8 & Broadleaved forest & 3 & 20.76 & 23.57 & 31.41 \\
\hline 9 & Coniferous forest & 4 & 14.76 & 17.81 & 23.13 \\
\hline 10 & Broadleaved forest & 3 & -1.67 & 14.72 & 14.82 \\
\hline 11 & Coniferous forest & 7 & 2.71 & 14.72 & 14.97 \\
\hline 12 & Broadleaved forest & 4 & 4.11 & 18.96 & 19.40 \\
\hline 13 & Coniferous forest & 4 & -4.61 & 16.84 & 17.46 \\
\hline 14 & Coniferous forest & 5 & -19.89 & 4.44 & 20.37 \\
\hline 15 & Coniferous forest & 4 & -16.31 & 16.33 & 23.08 \\
\hline 16 & Coniferous forest & 4 & -14.76 & 6.61 & 16.18 \\
\hline 17 & Broadleaved forest & 9 & -15.91 & 11.00 & 19.34 \\
\hline 18 & Broadleaved forest & 8 & -21.33 & 14.34 & 25.70 \\
\hline 19 & Broadleaved forest & 8 & -17.73 & 6.53 & 18.89 \\
\hline 20 & Coniferous forest & 3 & -19.48 & 3.59 & 19.81 \\
\hline 21 & Broadleaved forest & 6 & -25.14 & 7.19 & 26.15 \\
\hline 22 & Broadleaved forest & 3 & -17.16 & 7.86 & 18.88 \\
\hline 23 & Coniferous forest & 4 & -18.51 & 1.59 & 18.58 \\
\hline 24 & Coniferous forest & 8 & -17.14 & 7.10 & 18.55 \\
\hline 25 & Broadleaved forest & 9 & -28.54 & -2.28 & 28.63 \\
\hline 26 & Broadleaved forest & 9 & -22.24 & 3.05 & 22.44 \\
\hline 27 & Broadleaved forest & 8 & -23.58 & 17.26 & 29.22 \\
\hline 28 & Broadleaved forest & 6 & --22.85 & 15.62 & 27.68 \\
\hline 29 & Broadleaved forest & 5 & -14.01 & 14.43 & 20.12 \\
\hline
\end{tabular}

3.2. Comparison of Single-Point Positioning Errors between Coniferous and Broadleaved Forest Species

To quantitatively analyze the impact of forest species (broadleaved or coniferous) on the positioning of the GNSS, the positioning accuracy of different multi-epoch data was evaluated and analyzed in more detail (Table 5). The RMSE $E_{x y}$ of the broadleaved forest species ranged from 15.85 to $24.58 \mathrm{~m}$, and that of the coniferous forest species ranged from 14.02 to $22.40 \mathrm{~m}$. The position error range of the coniferous forest species was slightly narrower than that of the broadleaved forest species. For the same amount of multi-epoch data, the RMSE $E_{x y}$ of the coniferous forest species was lower than that of the broadleaved forest species, and the positioning accuracy was higher. The positioning errors of the GNSS in the $x$ - and $y$-axis directions under the broadleaved forest were greater than those under the coniferous forest, which were -9.26 and 11.94 , and -4.95 and $11.07 \mathrm{~m}$, respectively. The highest positioning accuracy was obtained in the total positioning time, with values of 15.11 and $12.13 \mathrm{~m}$, respectively.

Table 5. Accuracy evaluation of single-point positioning error in the coniferous forest and broadleaf forest.

\begin{tabular}{|c|c|c|c|c|c|c|c|c|c|c|}
\hline \multirow[b]{2}{*}{ Number of Epochs } & \multicolumn{5}{|c|}{ Broadleaved Forest/m } & \multicolumn{5}{|c|}{ Coniferous Forest/m } \\
\hline & $\begin{array}{c}B I A S \\
x\end{array}$ & $\begin{array}{c}\text { BIAS } \\
y\end{array}$ & $\begin{array}{c}R M S E \\
x\end{array}$ & $\begin{array}{c}\text { RMSE } \\
y\end{array}$ & $\begin{array}{c}\text { RMSE } \\
x y\end{array}$ & $\begin{array}{c}B I A S \\
x\end{array}$ & $\begin{array}{c}\text { BIAS } \\
y\end{array}$ & $\begin{array}{c}R M S E \\
x\end{array}$ & $\begin{array}{c}R M S E \\
y\end{array}$ & $\begin{array}{c}\text { RMSE } \\
x y\end{array}$ \\
\hline 1 & -12.54 & 21.06 & 26.17 & 22.89 & 24.58 & -10.75 & 17.90 & 24.12 & 20.63 & 22.44 \\
\hline 2 & -13.93 & 21.62 & 28.05 & 23.33 & 25.80 & -11.20 & 16.45 & 23.56 & 19.22 & 21.50 \\
\hline 5 & -10.11 & 22.12 & 26.13 & 24.99 & 25.57 & -8.02 & 16.70 & 20.34 & 18.17 & 19.29 \\
\hline 10 & -11.39 & 19.01 & 22.68 & 20.33 & 21.53 & -7.08 & 16.10 & 19.56 & 17.24 & 18.44 \\
\hline 30 & -10.81 & 18.89 & 21.65 & 20.83 & 21.24 & -5.27 & 14.61 & 18.40 & 15.68 & 17.10 \\
\hline
\end{tabular}


Table 5. Cont.

\begin{tabular}{|c|c|c|c|c|c|c|c|c|c|c|}
\hline \multirow[b]{2}{*}{ Number of Epochs } & \multicolumn{5}{|c|}{ Broadleaved Forest/m } & \multicolumn{5}{|c|}{ Coniferous Forest $/ \mathrm{m}$} \\
\hline & $\begin{array}{c}B I A S \\
\quad x\end{array}$ & $\begin{array}{c}B I A S \\
y\end{array}$ & $\begin{array}{c}R M S E \\
x\end{array}$ & $\begin{array}{c}R M S E \\
y\end{array}$ & $\begin{array}{c}\text { RMSE } \\
x y\end{array}$ & $\begin{array}{c}B I A S \\
x\end{array}$ & $\begin{array}{c}B I A S \\
y\end{array}$ & $\begin{array}{c}R M S E \\
x\end{array}$ & $\begin{array}{c}R M S E \\
y\end{array}$ & $\begin{array}{c}\text { RMSE } \\
x y\end{array}$ \\
\hline 60 & -10.25 & 16.31 & 20.89 & 17.65 & 19.34 & -4.87 & 13.90 & 17.84 & 15.06 & 16.51 \\
\hline 90 & -9.91 & 15.57 & 20.48 & 16.89 & 18.77 & -4.72 & 13.56 & 17.48 & 14.75 & 16.17 \\
\hline 120 & -9.73 & 15.08 & 20.18 & 16.40 & 18.39 & -4.60 & 13.28 & 17.22 & 14.50 & 15.92 \\
\hline 240 & -9.27 & 13.87 & 19.41 & 15.22 & 17.44 & -4.37 & 12.59 & 16.52 & 13.88 & 15.26 \\
\hline 300 & -9.11 & 13.47 & 19.13 & 14.83 & 17.12 & -4.28 & 12.33 & 16.24 & 13.64 & 15.00 \\
\hline 400 & -8.90 & 12.89 & 18.72 & 14.29 & 16.65 & -4.12 & 11.94 & 15.83 & 13.29 & 14.62 \\
\hline 500 & -8.71 & 12.32 & 18.31 & 13.76 & 16.20 & -3.90 & 11.56 & 15.30 & 12.95 & 14.18 \\
\hline total & -9.26 & 11.94 & 17.95 & 13.44 & 15.85 & -4.95 & 11.07 & 15.32 & 12.59 & 14.02 \\
\hline
\end{tabular}

\subsection{Verification and Analysis of the Positioning Error Model}

The construction and accuracy of the maximum positioning error model were evaluated for the different forest types. Table 6 provides the model regression analysis results of the general model, the coniferous forest model, and the broadleaved forest model. From the analysis results of the three models, the regression analysis coefficient $\left(R^{2}\right.$ adj $\left.=0.701\right)$ of the coniferous forest model was found to be significantly higher than those of the general model $\left(R^{2}\right.$ adj $\left.=0.579\right)$ and the broadleaved forest model $\left(R^{2}{ }_{\text {adj }}=0.544\right)$. The independent variable factors of the three models were multi-epoch data and tree canopy. The model analysis results showed that the positioning error with the GNSS was very significant. The parameters of the different models are also shown in Table 6.

Table 6. Model regression analysis results.

\begin{tabular}{lccccccc}
\hline Model & $\mathbf{m}$ & $\mathbf{a}$ & $\mathbf{b}$ & $\mathbf{b}_{\mathbf{1}}$ & $\mathbf{b}_{\mathbf{2}}$ & $\mathbf{R}^{\mathbf{2}} \mathbf{\text { adj }}$ & Significance \\
\hline General & 29 & 31.47 & 3.25 & 0 & 0 & 0.579 & 0.000 \\
Coniferous & 12 & 28.99 & 0 & 3.54 & 0 & 0.701 & 0.000 \\
Broadleaved & 17 & 32.81 & 0 & 0 & 3.17 & 0.544 & 0.000 \\
\hline
\end{tabular}

\section{Discussion}

In this study, we quantitatively analyzed and determined the influences of positioning time, forest type, and tree canopy on positioning errors using single-point positioning data in a GNSS under different forest types, and further built the maximum error model of different forest types within a certain positioning time. The results showed that with an increase in positioning time, the positioning accuracy of a single point under the forest improved considerably and gradually stabilized. The positioning accuracy under the tree canopy increased obviously as the amount of multi-epoch data increased, but the overall impact was an increase in positioning time. Single-point positioning in the different forest types achieved the highest positioning accuracy when the positioning time was approximately $10 \mathrm{~min}$. Figure 6 shows the changes in GNSS positioning accuracy in the longitude and latitude directions with positioning time for the different forest types (coniferous and broadleaved forests). As shown in the figure, the positioning error ranges of the GNSS in the longitude and latitude directions under the coniferous forest were narrow and tended to more quickly achieve stable states. Compared with the results for the coniferous forest, the GNSS had larger positioning error deviations in the longitude and latitude directions under the broadleaved forest, and single-point positioning tended to achieve stability more slowly. However, the positioning errors in both the coniferous and broadleaved forests decreased as the positioning time increased, which also indicates that increases in positioning time help improve the accuracy of single-point positioning. Figure 7 depicts the distributions of the residuals of the carrier phase and pseudo-range received by different satellites for the coniferous and broadleaved forests with positioning time. As shown in the figure, the carrier phase and pseudo-range information received by the receiver from different satellites differed noticeably, which was closely related to 
the satellite distribution in the sky at the time of positioning and the occlusion of the tree crown or other obstacles. The residuals of the carrier phase and pseudo-range did not decrease significantly with increasing positioning time, which indicates that the satellite signals received by the receiver in the positioning process did not increase with increasing positioning time. This information is consistent with the description in the results. The positioning accuracy of the GNSS for the coniferous forest was higher than that for the broadleaved forest, which is consistent with the results of Deckert and Bolstad [4], but also differed from those of Deckert and Bolstad [4], i.e., GNSS positioning error was not affected by crown type. In this study, the minimum positioning error, $12.13 \mathrm{~m}$ in the coniferous forest, is significantly higher than that in a coniferous forest determined by Næsset [1] of $1.98 \mathrm{~m}$. Many factors contributed to this large difference; among them, geographical location may be one of the most important.
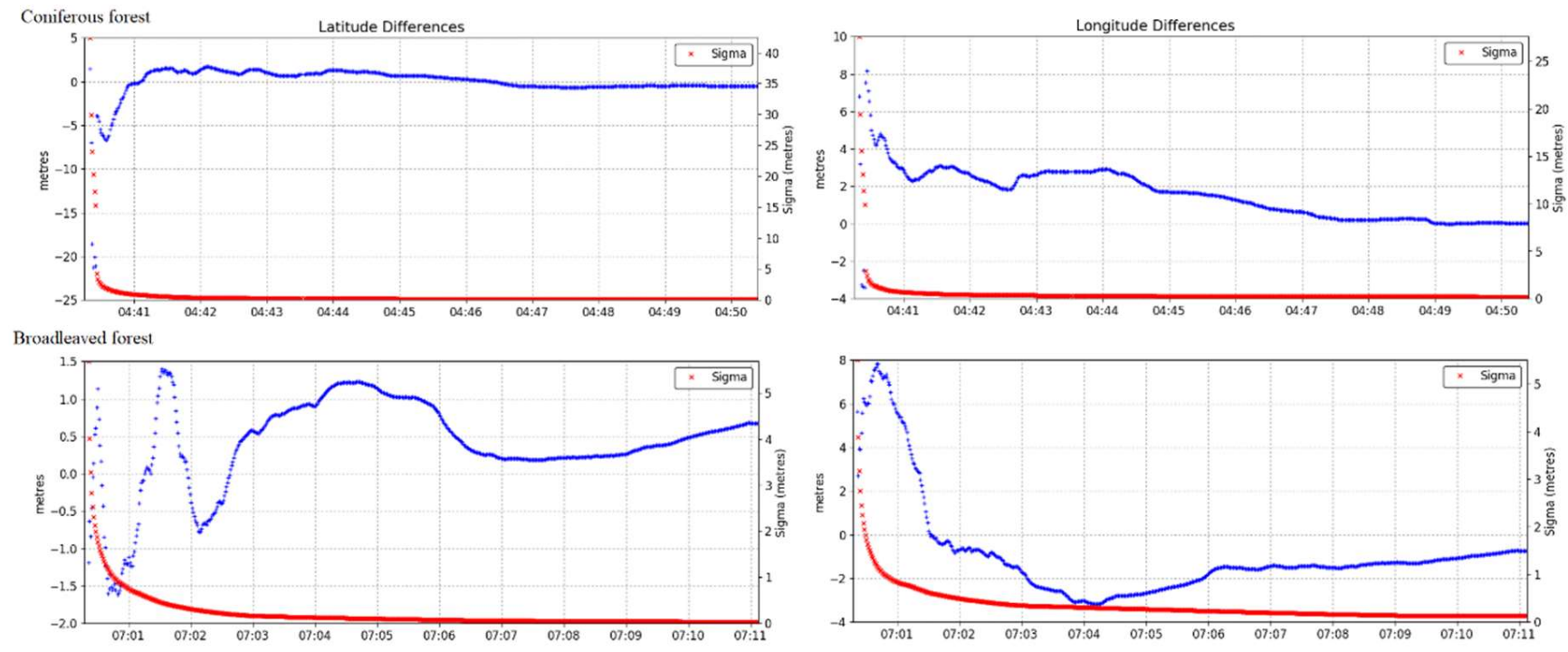

Figure 6. Variation in the positioning accuracy of the Galaxy 6 GNSS for a coniferous forest and a broadleaved forest over time.

The results of this study showed that the positioning error of a single point was relatively less affected by the size of a single crown. Previous studies have found that the positioning accuracy of a GNSS is strongly affected by stand density and canopy size $[18,28-31]$. The GNSS performed single-point positioning under a coniferous forest and a broadleaved forest with different canopy sizes, but the positioning accuracy did not improve as the tree canopy decreased, and there was no strong correlation between the factors. However, the regression analysis of the constructed model showed that measurement time, tree canopy size, and positioning error were extremely significant, which agreed with our hypothesis. The determination coefficients of the regression analysis for the general model, coniferous model and broadleaf model were $0.579,0.701$, and 0.544 , respectively, indicating that the coniferous forest model had the most accurate model prediction effect. One possible reason for this finding is that conifers have more space between their crowns, which helps pick up stable satellite signals to improve positioning accuracy. The model's prediction accuracy was slightly lower than those of different models constructed by Holden et al. [31] using differential GNSS data $\left(R^{2}=0.81, R^{2}=0.74\right.$, and $\mathrm{R}^{2}=0.78$ ). However, previous studies mainly focused on the impact of forest canopy on GNSS positioning and did not establish an effective GNSS positioning error prediction model $[29,32,33]$. The maximum error model established in this study can effectively predict the maximum positioning error of a particular positioning time to determine whether the positioning error meets the positioning accuracy requirements in advance.

In this study, a quantitative analysis of positioning errors of a GNSS system in coniferous and broadleaved forests was conducted. The relationship between positioning errors 
and positioning time length was described in detail. In future studies, we will select different geographic locations, terrain conditions, satellite systems, and types of receivers to test and verify the impact of these factors on positioning errors and consider how to quantify these effects.
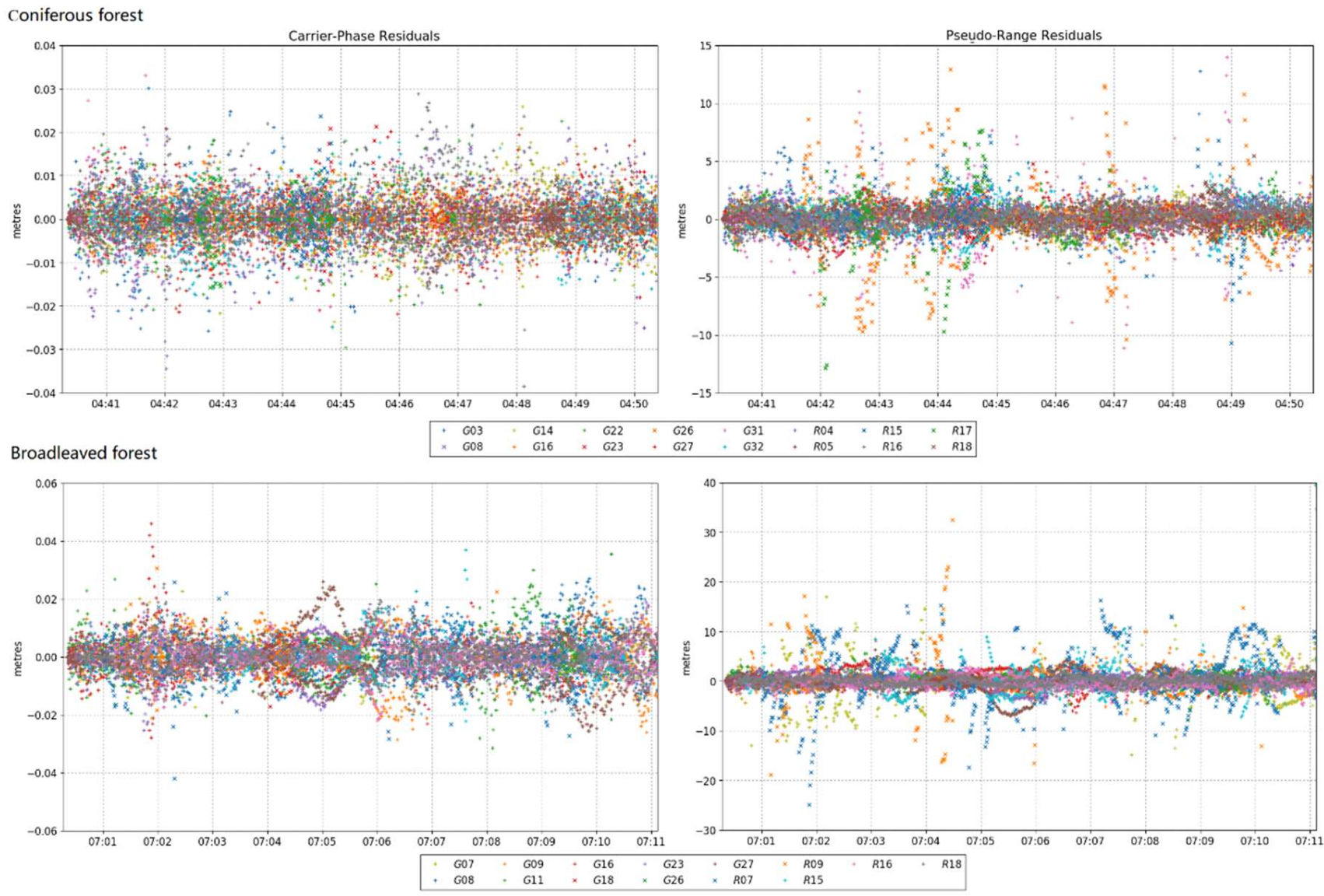

Figure 7. Distributions of carrier phase residuals and pseudo-range residuals with positioning time for single-point positioning in coniferous and broadleaved forests by a GNSS.

\section{Conclusions}

In this study, single-point positioning coordinates were obtained with the Galaxy 6 GNSS under different conditions. The results were compared with reference coordinates measured with a total station, and the influences of different forest types, positioning time, and crown size on the single-point positioning accuracy were determined. Finally, the maximum positioning error model of single-point positioning with a GNSS for a certain period of time was developed. The results showed that the different forest types had certain impacts on the positioning accuracy of the GNSS. The highest positioning accuracies of the GNSS under the coniferous and broadleaved forests were 15.11 and $12.13 \mathrm{~m}$, respectively. This result showed that the positioning error of the GNSS was less affected by the coniferous forest, and the single-point positioning accuracy obtained was higher. For a certain positioning time, the positioning accuracy increased as the positioning time increased; the more the epoch data, the higher the positioning accuracy, which is important for obtaining the locations of trees in forests. Our study also showed that single crown size had little effect on the GNSS positioning error. In the future, we will obtain more experimental data to verify the results of this experiment and reduce unintentional errors. The maximum positioning error model developed in this study can effectively predict the positioning error for a forest in a forest resource inventory and determine in advance whether the positioning accuracy meets the accuracy requirements of the forest 
resource survey. In the future, we will conduct in-depth experiments under different terrain conditions and in different geographical locations to verify the impact of these factors on the positioning accuracy of the GNSS.

Author Contributions: Conceptualization, T.F., S.C., and Z.F.; methodology, T.F., S.C., and C.S.; validation, T.F., S.C., and Y.T.; formal analysis, T.F. and S.C.; investigation, C.S. and Y.T.; writing-original draft preparation, T.F. and S.C.; writing-review and editing, T.F., S.C., and Y.T.; proofreading, T.F., S.C., and Y.T. All authors have read and agreed to the published version of the manuscript.

Funding: This research was funded by the Fundamental Research Funds for the Central Universities, grant number 2015ZCQ-LX-01.

Acknowledgments: The authors wish to thank L.S., Y.F., and Z.Z. for helping to collect data.

Conflicts of Interest: The authors declare no conflict of interest.

\section{References}

1. Næsset, E.; Gjevestad, J.G. Performance of gps precise point positioning under conifer forest canopies. Photogramm. Eng. Remote Sens. 2008, 74, 661-668. [CrossRef]

2. Chen, Q. Effects of forest canopy, landform and distance on GPS positioning accuracy. Technol. Soil Water Conserv. 1999, 58-61. (In Chinese)

3. Muscarella, R.; Kolyaie, S.; Morton, D.C.; Zimmerman, J.K.; Uriarte, M. Effects of topography on tropical forest structure depend on climate context. J. Ecol. 2020, 108, 145-159. [CrossRef]

4. Deckert, C.; Bolstad, P.V. Forest canopy, terrain, and distance effects on global positioning system point accuracy. Photogramm. Eng. Remote Sens. 1996, 62, 317-321.

5. Chen, S.; Liu, H.; Feng, Z.; Shen, C.; Chen, P. Applicability of personal laser scanning in forestry inventory. PLoS ONE 2019, 14, e0211392. [CrossRef]

6. Fan, Y.; Feng, Z.; Mannan, A.; Khan, T.U.; Shen, C.; Saeed, S. Estimating tree position, diameter at breast height, and tree height in real-time using a mobile phone with rgb-d slam. Remote Sens. 2018, 10, 1845. [CrossRef]

7. Kaartinen, H.; Hyyppä, J.; Vastaranta, M.; Kukko, A.; Jaakkola, A.; Yu, X.; Pyörälä, J.; Liang, X.; Liu, J.; Wang, Y. Accuracy of kinematic positioning using global satellite navigation systems under forest canopies. Forests 2015, 6, 3218-3236. [CrossRef]

8. Prusty, S.; Sahoo, S. Detection of forest fire by using gsm \& gps technology. Int. J. Intell. Comput. Appl. Sci. 2017, 5, $2322-2353$.

9. Shrestha, H.L. Using global positioning systems (gps) and geographic information systems (gis) in participatory mapping of community forest in nepal. Electron. J. Inf. Syst. Dev. Ctries. 2006, 25, 1-11. [CrossRef]

10. Ying, L.; Zhu, Y.; Li, Y.; Chao, N. The embedded information acquisition system of forest resource. Telkomnika Indones. J. Electr. Eng. 2012, 10, 1843-1848.

11. Keefe, F.R.; Wempe, M.A.; Becker, M.R.; Zimbelman, G.E.; Nagler, S.E.; Gilbert, L.S.; Caudill, C.C. Positioning methods and the use of location and activity data in forests. Forests 2019, 10, 458. [CrossRef]

12. Toledo-Moreo, R.; Betaille, D.; Peyret, F.; Laneurit, J. Fusing gnss, dead-reckoning, and enhanced maps for road vehicle lane-level navigation. IEEE J. Sel. Top. Signal Process. 2009, 3, 798-809. [CrossRef]

13. Weaver, S.A.; Ucar, Z.; Bettinger, P.; Merry, K. How a gnss receiver is held may affect static horizontal position accracy. PLoS ONE 2015, 10, e0124696.

14. Pau, L.-F.; Klamerus-Iwan, A.; Kormanek, M.; Gołąb, J.; Owsiak, K. Robotic forest harvesting process using gnss satellite positioning data: Effects of gnss inaccuracies in forest environments. In Electronic Journal of Polish Agricultural Universities; Electronic Journal of Polish Agricultural Universities: Krakow, Poland, 2016.

15. Schubert, F.; Fleury, B.; Robertson, P.; Prieto-Cerdeira, R.; Steingass, A.; Lehner, A. Modeling of multipath propagation components caused by trees and forests. In Proceedings of the Fourth European Conference on Antennas and Propagation, Barcelona, Spain, 12-16 April 2010; pp. 1-5.

16. Koh, I.; Sarabandi, K. Performance characterization of gps receivers under tree canopies. In Proceedings of the IEEE Antennas and Propagation Society International Symposium. Transmitting Waves of Progress to the Next Millennium. 2000 Digest. Held in conjunction with: USNC/URSI National Radio Science Meeting, Salt Lake City, UT, USA, 16-21 July 2000; Volume 431, pp. 438-441.

17. Li, C. Study on the Stability of Handheld GPS Receiver in Forest Region. J. Shenzhen Polytech. 2003, 2, 6-10. (In Chinese)

18. Rodríguez-Pérez, J.; Alvarez-Taboada, F.; Sanz-Ablanedo, E. Assessment of low-cost gps receiver accuracy and precision in forest environments. J. Surv. Eng. 2007, 133, 159-167. [CrossRef]

19. Hasegawa, H.; Yoshimura, T. Application of dual-frequency gps receivers for static surveying under tree canopies. J. For. Res. 2003, 8, 103-110. [CrossRef]

20. Brach, M.; Zasada, M. The effect of mounting height on gnss receiver positioning accuracy in forest conditions. Croat. J. For. Eng. 2014, 35, 245. 
21. Hoppus, M.; Lister, A. The status of accurately locating forest inventory and analysis plots using the global positioning system. In Proceedings of the Seventh Annual Forest Inventory and Analysis Symposium, Washington, DC, USA, 3-6 October 2005.

22. Sigrist, P.; Coppin, P.; Hermy, M. Impact of forest canopy on quality and accuracy of gps measurements. Int. J. Remote Sens. 1999, 20, 3595-3610. [CrossRef]

23. Abdi, E.; Mariv, H.S.; Deljouei, A.; Sohrabi, H. Accuracy and precision of consumer-grade gps positioning in an urban green space environment. For. Sci. Technol. 2014, 10, 141-147. [CrossRef]

24. Tomaštík, J.; Saloň, Š.; Piroh, R. Horizontal accuracy and applicability of smartphone gnss positioning in forests. Forestry 2017, 92, 187-198. [CrossRef]

25. Feng, Z.K.; You, X.X. Study on the Influence of Forest Crown Mountain on GPS Measurement Accuracy. In New Century New Opportunities New Challenges-Knowledge Innovation and High-Tech Industry Development; Academic department of Chinese Association of Science and Technology: Changchun, Jilin, China, 2001; Volume 2. (In Chinese)

26. Sawaguchi, I.; Saitoh, Y.; Tatsukawa, S. A study of the effects of stems and canopies on the signal to noise ratio of gps signals. J. For. Res. 2005, 10, 395-401. [CrossRef]

27. Yin, X.; Bao, Q.; Wang, H.; Meng, Y.; Wang, Y. Spatial Continuity Test Method and Device of Remote Sensing Satellite Data; Intellectual Property Press: Beijing, China, 2020. (In Chinese)

28. Hasegawa, H.; Yoshimura, T. Estimation of gps positional accuracy under different forest conditions using signal interruption probability. J. For. Res. 2007, 12, 1-7. [CrossRef]

29. Yoshimura, T.; Hasegawa, H. Comparing the precision and accuracy of gps positioning in forested areas. J. For. Res. 2003, 8, 147-152. [CrossRef]

30. Wing, M.G. Consumer-grade gps receiver measurement accuracy in varying forest conditions. Res. J. For. 2011, 5, 78-88. [CrossRef]

31. Holden, N.M.; Martin, A.A.; Owende, P.M.O.; Ward, S.M. A method for relating gps performance to forest canopy. Int. J. For. Eng. 2001, 12, 51-56. [CrossRef]

32. Morales, Y.; Tsubouchi, T. In Dgps, rtk-gps and starfire dgps performance under tree shading environments. In Proceedings of the 2007 IEEE International Conference on Integration Technology, Shenzhen, China, 20-24 March 2007.

33. Lee, I.-S.; Ge, L. The performance of rtk-gps for surveying under challenging environmental conditions. Earth Planets Space 2006, 58, 515-522. [CrossRef] 